\title{
As funções de interpretação biológica no acúmulo de biomassa e grãos de trigo no aproveitamento de nitrogênio sobre o resíduo de soja
}

\author{
Ana Paula Brezolin* Juliane S. P. Costa Darciane I. M. Kremer \\ Anderson Marolli Rubia D. Mantai José Antonio G. da Silva \\ Departamento de Ciências Exatas e Engenharias, DCEEng, UNIJUÍ \\ 98700-000, Ijuí, RS \\ E-mail: ana.brezolin@unijui.edu.br
}

\begin{abstract}
RESUMO
O trigo (Triticum aestivum L.) é uma espécie muito cultivada mundialmente, podendo ser utilizado de várias formas. Este se constitui em uma importante cultura na rotação e/ou sucessão cultural nas unidades de produção agropecuárias. Por ser da família das Poaceas, não tem como característica a fixação biológica de nitrogênio, necessitando assim, que esse nutriente seja suprido através de fertilizantes para completar seus processos biológicos que determinarão o crescimento e reprodução da planta, como pode ser observado em [2]. Portanto, a adubação nitrogenada se insere como um fator importante. Os sistemas de cultivo devem ser considerados no intuito de prever a dose e o momento mais ajustado de fornecimento do adubo. Para um elevado rendimento torna-se fundamental o adequado ajuste das cultivares disponíveis ao produtor com as distintas técnicas de manejo, como a dose de adubação nitrogenada de cobertura e os diferentes ambientes de cultivo da unidade agrícola. O objetivo do estudo foi à modelagem matemática do desempenho das cultivares de trigo classe industrial tipo pão (BRS Guamirim) e classe melhorador (Fundacep Nova Era) sob efeito de doses e épocas de aplicação de nitrogênio $(\mathrm{N})$ no sistema soja/trigo, a partir de modelos de diferenciação de médias e equações lineares.

O presente trabalho foi desenvolvido na área experimental do IRDeR (Instituto Regional de Desenvolvimento Rural) pertencente ao DEAg (Departamento de Estudos Agrário) da UNIJUÍ, durante o ano agrícola 2012. O delineamento experimental foi o de blocos casualizados com quatro repetições, seguindo um modelo fatorial $2 \times 3 \times 4$, sendo duas cultivares de trigo (BRS Guamirim e Fundacep Nova Era), três épocas de adubação nitrogenada $\left(\mathrm{V}_{3}, \mathrm{~V}_{6}\right.$ e $\left.\mathrm{R}_{1}\right)$ e quatro doses de aplicação da adubação nitrogenada (testemunha (zero), 30, 60, $120 \mathrm{~kg}$ nitrogênio ha $^{-1}$ ). As parcelas foram constituídas por cinco linhas espaçadas $0,20 \mathrm{~m}$ entre si e cinco metros de comprimento, resultando em cinco metros quadrados por parcela. As variáveis mensuradas foram: Matéria seca total (MST) e Rendimento de Grãos (RG).

Foi observado que a taxa de produção de biomassa em cada tratamento mostrou uma tendência linear significativa confirmada pela probabilidade de t a $5 \%$ no coeficiente angular $\left(\mathrm{b}_{\mathrm{i}} \mathrm{x}\right)$, indicando adequado ajuste do modelo sobre o resíduo de soja.

$\mathrm{Na}$ análise da maior taxa de biomassa acumulada por unidade de dia, elevada produção de grãos foi obtida nas épocas $\mathrm{V}_{3} / \mathrm{V}_{6}$ e $\mathrm{V}_{3} / \mathrm{R}_{1}$ com 30 e $60 \mathrm{~kg}$ de $\mathrm{N} \mathrm{ha}^{-1}$ respectivamente. Foi verificado em [3], que o parcelamento da adubação nitrogenada implica em maior recuperação do nutriente pela planta e maior produtividade quando comparados com uma única aplicação. Além disso, foi constatado em [1] que a época de aplicação de N, considerando a mesma dose, não influenciou na produção de matéria seca e $\mathrm{N}$ acumulado pelas culturas, existindo variações somente entre as doses totais aplicadas, independentemente das épocas.

Os valores médios de produtividade de grãos mostraram os maiores rendimentos para a maior dose de $\mathrm{N}$ utilizada $\left(120 \mathrm{~kg} \mathrm{ha}^{-1}\right)$ nas três condições avaliadas. Foi constatado em [4], que o incremento na dose de $\mathrm{N}$ até a aplicação de $120 \mathrm{~kg} \mathrm{ha}^{-1}$ aumenta a produtividade de grãos de trigo, independentemente da época de aplicação e da fonte de $\mathrm{N}$.
\end{abstract}

* Estudante de Pós-Graduação do Curso de Modelagem Matemática da UNIJUÍ e bolsista FAPERGS. 
Tabela 1. Resumo da análise de variância de equação de regressão e seus parâmetros para a matéria seca total (MST) em trigo com os valores médios gerais de rendimento de grãos (RG) sobre resíduo de soja. UNIJUI, 2014.

\begin{tabular}{|c|c|c|c|c|c|}
\hline Dose & Condição & $\begin{array}{c}\text { Equação } \\
\mathrm{MST}=\mathrm{b}_{0} \pm \mathrm{b}_{1} \mathrm{x}\end{array}$ & $\begin{array}{l}\mathrm{R}^{2} \\
\%\end{array}$ & $\begin{array}{c}P \\
b_{i} X\end{array}$ & $\begin{array}{c}\mathrm{RG} \\
\mathrm{kg} \mathrm{ha}^{-1}\end{array}$ \\
\hline \multirow[t]{2}{*}{0} & - & $1604+72,6 x$ & 85 & $*$ & 1685 \\
\hline & $\mathrm{V}_{3}$ & $1134+68,7 x$ & 75 & $*$ & $2298 \mathrm{~b}$ \\
\hline \multirow[t]{3}{*}{30} & $\mathrm{~V}_{3} / \mathrm{V}_{6}$ & $1811+83,2 x$ & 83 & $*$ & $2544 \mathrm{a}$ \\
\hline & $\mathrm{V}_{3} / \mathrm{R}_{1}$ & $1614+77,3 x$ & 61 & $*$ & $2273 \mathrm{~b}$ \\
\hline & $\mathrm{V}_{3}$ & $1570+78,9 x$ & 68 & $*$ & $2144 \mathrm{~b}$ \\
\hline \multirow[t]{3}{*}{60} & $\mathrm{~V}_{3} / \mathrm{V}_{6}$ & $1307+74,5 x$ & 73 & $*$ & $2460 \mathrm{~b}$ \\
\hline & $\mathrm{V}_{3} / \mathrm{R}_{1}$ & $1763+82,1 x$ & 72 & $*$ & $2611 \mathrm{a}$ \\
\hline & $\mathrm{V}_{3}$ & $1434+75,0 \mathrm{x}$ & 74 & $*$ & $2875 \mathrm{a}$ \\
\hline \multirow[t]{2}{*}{120} & $\mathrm{~V}_{3} / \mathrm{V}_{6}$ & $1327+78,5 x$ & 75 & $*$ & $2788 \mathrm{a}$ \\
\hline & $\mathrm{V}_{3} / \mathrm{R}_{1}$ & $2245+85,5$ & 83 & $*$ & $2846 \mathrm{a}$ \\
\hline
\end{tabular}

$\mathrm{V}_{3}=$ colar formado na $3^{\mathrm{a}}$ folha do colmo principal, $\mathrm{V}_{3} / \mathrm{V}_{6}=$ Colar formado na $6^{\mathrm{a}}$ folha do colmo principal e $V_{3} / R_{1}=$ Diferenciação da espiga; $R^{2}=$ coeficiente de determinação; $\mathrm{Pb}_{\mathrm{ix}}=$ probabilidade da significância de inclinação da reta; Médias seguidas pela mesma letra minúscula não diferem significativamente em nível de 5\% de probabilidade de erro pelo modelo de Scott \& Knott.

$\mathrm{Na}$ Tabela 1 pode ser observado que as funções lineares e estimativas com probabilidade das médias permitiram analisar que as doses de $\mathrm{N}$ que corresponde a maior eficiência agronômica muitas vezes não corresponde a maior eficiência econômica. Neste contexto, estudos realizados em trigo fornecem indicativos que pequenas doses limitam a produtividade, mas em altas doses podem levar ao acamamento, dificultando a colheita e causando queda na produtividade.

Palavras-chave: Triticum aestivum L., Adubação Nitrogenada, Modelos Matemáticos.

\section{Referências}

[1] Da Ros, C.O.; Salet, R.L.; Porn, R.L.; Machado, J.N.C. Disponibilidade de nitrogênio e produtividade de milho e trigo com diferentes métodos de adubação nitrogenada no sistema plantio direto. Ciência Rural, v.33, p.799-804, 2003.

[2] Prando, Andre Mateus et al. Características produtivas do trigo em função de fontes e doses de nitrogênio. Pesq. Agropec. Trop., Goiânia, v. 43, n. 1, p. 34-41, 2013.

[3] S. L. ; Berns, A.C; Almeida, M.L.; Zanin, C. G.; Shweitzer, C. Características agronômicas de trigo em resposta à época da adubação nitrogenada de cobertura. Ciência Rural, v. 37, p. 1564-1570, 2007.

[4] T. Filho, Marcelo Carvalho Minhoto et al. Doses, fontes e épocas de aplicação de nitrogênio em trigo irrigado em plantio direto. Pesq. agropec. bras. [online]. 2010, vol.45, n.8, pp. 797 804. ISSN 0100-204X. 